\title{
Mathematical Modelling and Experimental Study of Straw co-Firing with Gas
}

\section{Inesa Barmina ${ }^{b}$, Harijs Kalis $^{a}$, Antons Kolmickovs ${ }^{b}$, Maksims Marinaki ${ }^{a}$, Liiva Ozola ${ }^{a}$, Uldis Strautins ${ }^{b}$, Raimonds Valdmanis ${ }^{b}$ and Maija Zake $^{b}$}

\author{
${ }^{a}$ Institute of Mathematics and Computer Science of University of Latvia \\ Raina bulvāris 29, Rīga LV-1459, Latvija \\ ${ }^{b}$ Institute of Physics, University of Latvia \\ 32 Miera Street, Salaspils-1, LV-2169, Latvia \\ E-mail(corresp.): kalis@lanet.lv \\ E-mail: inesa.barmina@lu.lv \\ E-mail: kolmic@lu.lv \\ E-mail: maksims.marinaki@lu.lv \\ E-mail: liiva@gmail.com \\ E-mail: uldis.strautins@lu.lv \\ E-mail: rww@inbox.Iv \\ E-mail: mzfi@sal.lv
}

Received September 17, 2018; revised July 2, 2019; accepted July 5, 2019

\begin{abstract}
The main goal of the present study is to promote a more effective use of agriculture residues (straw) as an alternative renewable fuel for cleaner energy production with reduced greenhouse gas emissions. With the aim to improve the main combustion characteristics at thermo-chemical conversion of wheat straw, complex experimental study and mathematical modelling of the processes developing when cofiring wheat straw pellets with a gaseous fuel were carried out. The effect of co-firing on the main gasification and combustion characteristics was studied experimentally by varying the propane supply and additional heat input into the pilot device, along with the estimation of the effect of co-firing on the thermal decomposition of wheat straw pellets, on the formation, ignition and combustion of volatiles $\left(\mathrm{CO}, \mathrm{H}_{2}\right)$.

A mathematical model has been developed using the environment of the Matlab (2D modelling) and MATLAB package "pdepe" (1D modelling) considering the variations in supplying heat energy and combustible volatiles $\left(\mathrm{CO}, \mathrm{H}_{2}\right)$ into the bottom of the combustor. Dominant exothermal chemical reactions were used to evaluate the effect of co-firing on the main combustion characteristics and composition of the
\end{abstract}

Copyright (C) 2019 The Author(s). Published by VGTU Press

This is an Open Access article distributed under the terms of the Creative Commons Attribution License (http://creativecommons.org/licenses/by/4.0/), which permits unrestricted use, distribution, and reproduction in any medium, provided the original author and source are credited. 
products $\mathrm{CO}_{2}$ and $\mathrm{H}_{2} \mathrm{O}$. The results prove that the additional heat from the propane flame makes it possible to control the thermal decomposition of straw pellets, the formation, ignition and combustion of volatiles and the development of combustion dynamics, thus completing the combustion of biomass and leading to cleaner heat energy production.

Keywords: reaction-diffusion equations, axisymmetric swirling flow, PDE system, Arrhenius kinetics.

AMS Subject Classification: 35K57; 80A30; 65N06; 65N40; 65N25; 65N35.

\section{Introduction}

The comprehensive research of swirling flows along with the estimation of their applicability to stabilize and control fuel combustion was started long ago and is associated with the studies of Syred, Gupta and Lilley [13], [23], [30]. These studies provide an analysis of the influence of the swirl level $(\mathrm{S})$ on the swirl flow dynamics and structure formation in the flame function zone.

Mathematical and physical fundamentals of chemistry, thermodynamics and fluid mechanics of combustion are given in Law [22] and Powers [26].

In terms of the EU 20/20/20 targets of cleaner energy production [11], the use of green energy sources, such as harvesting (wood) and agricultural (straw) residues [3], Barmina et al. [4], Abricka et al. [1], Glithero et al. [12] has become very important. Due to the rapidly increasing consumption of harvesting residues, there is a growing demand for wider use of agricultural residues (wheat or rape straw) for energy production. The use of agricultural residues as a fuel is more problematic if compare with harvesting residues, and can decrease energy production per mass of burned fuel, enhance the emission of polluting $\mathrm{CO}$ and $\mathrm{NOx}$ along with the enhanced formation of ash, thus limiting the applicability of straw for clean energy production (Glithero et al. [12], Vassilev et al. [32]).

In order to eliminate the problems caused by the use of straw for heat production, fuel mixture combined combustion processes are being developed providing the co-combustion of straw with solid [25], [31] or gaseous (Brown et al. [7]) fuel additives.

In the course of the studies of multi-fuel combined gasification/combustion processes, it has been found [7], [25], that by varying the proportions of the fuels in the mixture, the composition of emissions, the ash formation, the structure and deposition on the heating surfaces can be controlled. With this account, to minimize the negative effects when straw is used as a fuel and to assure the effective control of the main combustion characteristics and products' composition, the present research combines experiment and mathematical modelling of the processes developing when co-firing straw with a gaseous fuel (propane) by varying the propane and additional heat energy supply into the device.

In Barmina et al. [3], the formation of flame composition and temperature profiles downstream the swirling flame flows was studied experimentally. In Kalis et al. [18], the studies of Choi, Rusak et al. [9], are continued by conducting a numerical investigation in a cylindrical pipe with an inviscid, axisymmetric, steady swirling flow in a low Mach number approximation. The 
thermophysical and chemical parameters are assumed constant. The single step exothermic chemical reaction is modelled by combining a fuel and an oxidant to produce the product and heat using Arrhenius kinetics. The pressure is omitted from the equations by introducing the stream function and the vorticity. The swirling flow with axial and azimuthal velocities at the inlet develops. For a hyperbolic type partial differential equaton (PDE) approximation, upwind differences in space are used. The approximation in time is implicid, and for solving the discreate vector problem the ADI Douglas-Rachford method [10] is used. The results of the calculation show that at the a Lewis number $L e \geq 1$ the increase in axial velocity leads to an increase in maximum temperature of the reaction (and to a decrease at $L e<1$ ).

A similar experiment in Zake et al. [34], is discussed. In Kalis et al. [19], a similar numerical experiment with the full Navier-Stokes equations for a viscous, incompressible axisymmetric swirling flow with the Reynolds number 100 in an axial external uniform magnetic field was performed. The MHD process is considered in the so-called inductionless approximation. The effect of gravitation is assumed. The following conclusions are drawn: if gravitation is concerned an external magnetic field the inlet flow is deflected towards the wall forming a prominent vortex that blocks the central part of the pipe; since the conductivity of hot gases, such as air, oxygen, hydrogen is very low, the MHD mechanism is not effective in practical applications of the gas combustion.

In Barmina et al. [5], experimental studies and mathematical modelling of the effects of electric and magnetic fields induced by the direct electric current in a coil electrode at the inlet of the combustor are carried out. The investigation continues the study of Choi et al. [9] and Kalis et al. [18] in magnetic fields. The results show the increase of the flow vorticity when increasing the magnetic field-induced Lorentz force.

In Barmina et al. [6], two exothermic reactions for the combustion of $\mathrm{H}_{2}$ and $C O$ are used for modelling by ANSYS Fluent CFD. The simulations gave an insight into the combustion process in cases when the proportion of the volatiles $\left(\mathrm{H}_{2}, \mathrm{CO}\right)$ corresponds to that of the biomass consisting of wood or wheat straw, or peat, giving the temperature and velocity distributions in the flame. The maximum flame temperature for the specified ratios 1:1 of the volume fraction of these chemical substances in the fuel mixture was obtained.

In [2], [14], [15], [17], the applied electric field induces an electric current between the walls of the combustor and the axially inserted electrode of different length. The perfect gas model is used to solve the inviscid, axisymmetric, steady swirling flow with axial and radial velocities and with circulation. The action of the electric body force results in reduction of the free flame length. The maximum field effect was achieved with a 10-20\% straw mass fraction in the fuel mixture (peat, wood, coal) [2], [15], [17].

In [16], [20] (Kalis et al.), the combustion process with Arrhenius kinetics is modelled using simple exothermic chemical reactions and taking into account the electrodynamic effects due to the action of the Lorentz force on the combustion process in a cylindrical pipe. A $2 \mathrm{D}$ axially symmetric nonstationary physical model for the inviscid (Reynolds number $R e=\infty$ ), compressible swirling flow of ideal gas with two components of velocity $u_{r}, u_{z}$, with circu- 
lation $v=r u_{\phi}$, density $\rho$, concentration of chemical species, temperature and electromagnetic force is analyzed. For the discrete approximation of the convective terms, the upwind differences in space are used. The stability for the finite difference approximation is proved. In [16], to stabilize the calculations of the MHD equations, the finite Reynolds number $(R e=1000)$ is considered. Increasing electrodynamic force leads to an increase in maximum velocity and in temperature of the gas flow.

In this paper, we consider a model taking into account the interplay of $1 \mathrm{D}$ and 2D laminar, axially symmetric compressible swirling flow $(R e \geq 10000)$ with the propane combustion using six different chemical reactions. The value of the finite Reynolds number $R e$ is used to stabilize the compressible gas dynamic flow. Modelling laminar flames requires the solution of the coupled equations of mass, momentum, species balance and energy with detailed thermodynamic and transport relations and finite-rate chemistry. These equations are solved for the density, velocities, species mass fractions, and for the temperature. The obtained numerical and experimental results are compared.

\section{Experimental studies}

\subsection{Experimental device}

The processes developing when co-firing propane and wheat straw were studied using a batch-size pilot setup, which combines a biomass gasifier filled with wheat straw pellets (1), the water-cooled sections of the combustor (3) and a propane flame burner (4) with two symmetric nozzles for propane flame injection into the setup (Figure 1).

The gasifier was filled with straw pellets, the thermal decomposition of which was initiated and sustained by the propane flame flow. The propane flame provided an external heat flux input due to the total produced heat energy varied from $6 \%$ up to $42 \%$.

The experimental study involved joint measurements of the wheat straw weight loss rate, measurements of the concentration of combustible volatiles entering the combustor, measurements of the axial and tangential flow velocity components and of the flame temperature, calorimetric measurements of the heat output from the gasifier and water-cooled sections of the combustor and of the produced heat energy per mass of burned pellets, and measurements of the products' composition $\left(\mathrm{CO}_{2}, \mathrm{CO}, \mathrm{H}_{2}, \mathrm{NO}\right.$, ppm), air excess ratio and combustion efficiency by a gas analyzer Testo 350 .

\subsection{Experimental results and discussion}

The thermo-chemical conversion of straw pellets in the device starts with drying, heating and thermal decomposition of pellets causing the weight loss of the pellets which depends on the external heat source provided by the propane supply into the setup $\left(q_{\text {prop }}[1 / \mathrm{min}]\right)$. According to the data of DTG and DTA analysis, the wheat straw thermal degradation below $630 \mathrm{~K}$ can be related to the development of the endothermic thermal decomposition of hemicelluloses 


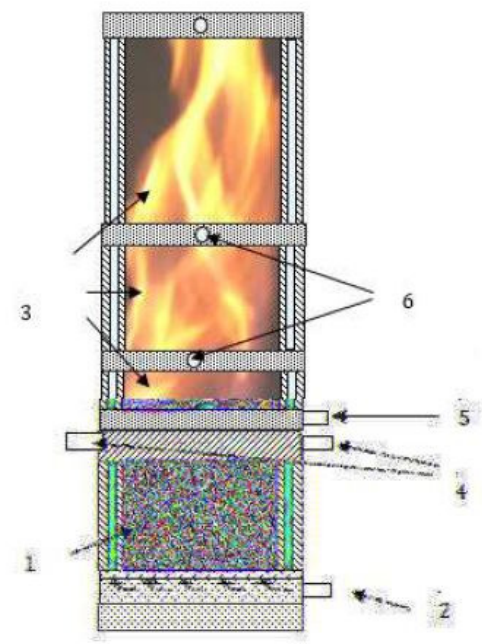

Figure 1. Principal schematic of the batch size pilot setup for gasification and co-firing of straw pellets with propane:

1 - gasifier of biomass pellets; 2 - primary air supply nozzle; 3 - water-cooled sections; 4 - propane flame injection nozzles; 5 - secondary air supply nozzle; 6 - orifices for diagnostic tools.

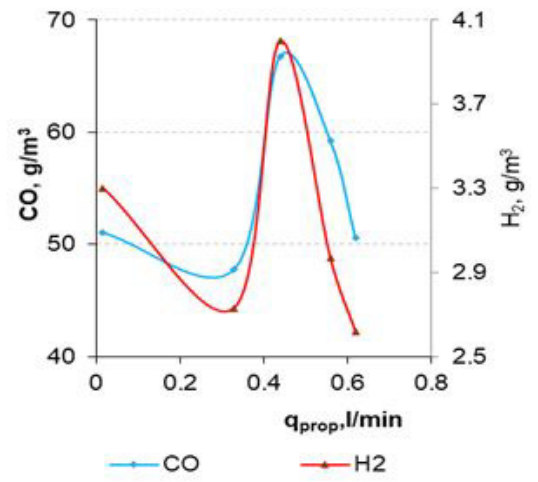

Figure 2. Concentration of $\mathrm{CO}, \mathrm{H}_{2}$ formed at the gasifier outlet vesrus the injection of propane.

with an intensive heat energy consumption from the propane flame flow accompanied by the correlating decrease of the produced heat energy inside the gasifier. A peak value of the wheat straw weight loss rate with a minimum value of the produced heat energy was observed for a propane supply of about $0.4-0.5 \mathrm{l} / \mathrm{min}$, which corresponds to an average heat power of the propane flame of $0.65-0.75 \mathrm{~kW}$. The measurements of the flame mix zone composition at the bottom of the combustor showed that the increase of the weight loss rate at the thermal decomposition of straw pellets correlated with the enhanced release of the combustible volatiles $\mathrm{CO}, \mathrm{H}_{2}$ (Figure 2). In the figure, one can see the peak value of the volatile mass fraction at the outlet of the gasifier which decreases when the propane supply into device exceeds $0.5 \mathrm{l} / \mathrm{min}$.

A slight decrease of the axial flow velocity to a minimum value was observed at a propane supply of about $0.5 \mathrm{l} / \mathrm{min}$, when the endothermic thermal decomposition of wheat straw pellets resulted in correlating increase to a maximum value of the weight loss rate of wheat straw pellets and of the mass fraction and axial mass flow of combustible volatiles. A more pronounced decrease of the wheat straw weight loss rate and mass flow of volatiles was observed when the propane supply into the device exceeded $0.5 \mathrm{l} / \mathrm{min}$ and the propane flame downstream convection restricted the upstream heat/mass transfer and the thermal decomposition of straw pellets. In Figure 4, one can see the concentration of $\mathrm{CO}_{2}$ versus the injection of propane.

Because of the ignition and flaming combustion of the volatiles entering the 
combustor, the flame temperature and the $\mathrm{CO}_{2}$ volume fraction in the products increase to the peak value (Figure 3 ).

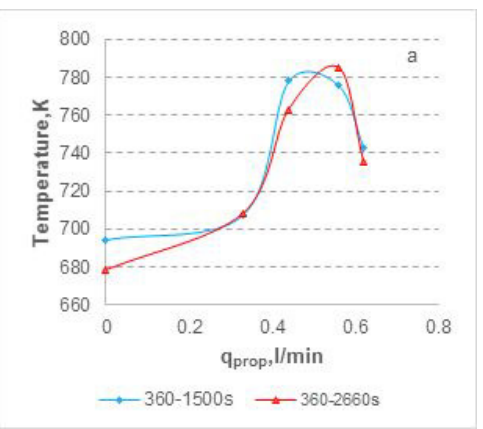

Figure 3. Effect of the propane supply on average values of the flame temperature (a).

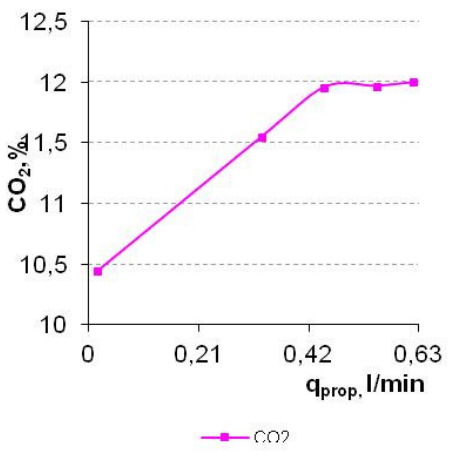

Figure 4. Volume fraction of $\mathrm{CO}_{2}$ versus the injection of propane.

The heat output from the setup and the heat energy produced during the burnout of the volatiles also increase, what allows to suggest that the co-firing of straw with propane assures the complete combustion of the volatiles. By analogy with the variations of the wheat straw weight loss rate and formation of combustible volatiles, the flame temperature and the $\mathrm{CO}_{2}$ volume fraction in the products reach peak values when the propane supply into the device approaches qprop $=0.5 \mathrm{l} / \mathrm{min}$ and then they tend to decrease with the further increase of the propane supply. However, the intensive development of the endothermic processes at the primary stage of biomass thermo-chemical conversion $(t<1500 \mathrm{~s})$ and the formation of volatiles $\left(\mathrm{CO}, \mathrm{H}_{2}\right)$ (Figures 5-6) affect the total amount of the produced heat energy, advancing a slight decrease after the propane supply into the device achieves $0.5 \mathrm{l} / \mathrm{min}$.

\section{Mathematical modelling of chemical reactions}

For a more throuoght analysis of the processes developing at the combustion of straw with gas, mathematical modelling and numerical simulation of the processes were carried out considering three types of second-order exothermic irreversible chemical reactions at the chemical conversion of combustible volatiles in order to assess their influence on the development of the combustion dynamics.

The mathematical modelling and numerical simulation of the main combustion characteristics were carried out using the experimental data on the mass fraction of the main reactants at the inlet of the combustor or at the outlet of the gasifier.

The gasification products $\mathrm{H}_{2}, \mathrm{CO}$ at the exothermal combustion of biomass pellets when co-firing wheat straw with propane were investigated. Taking into 


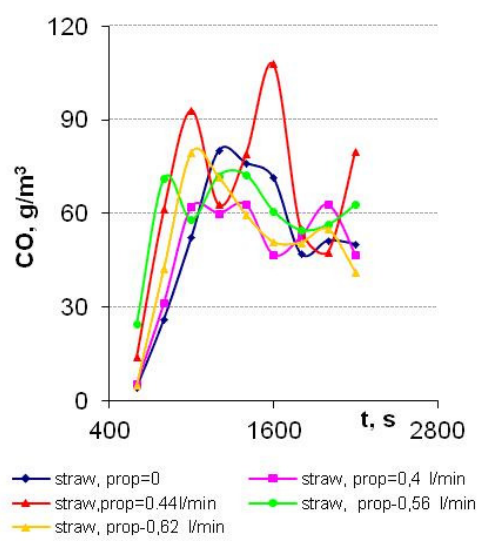

Figure 5. Effect of the propane supply on the $C O$ concentration at the bottom of the combustor.

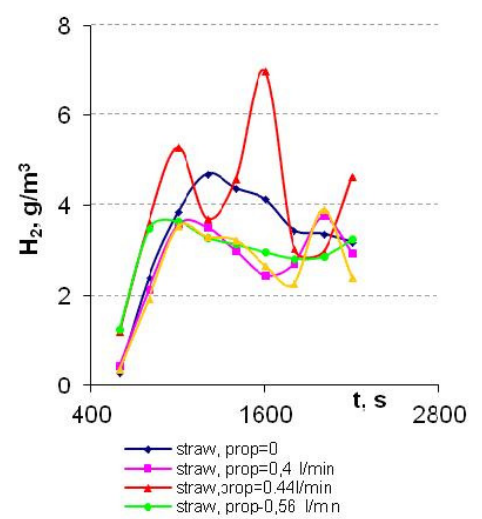

Figure 6. Effect of the propane supply on the $H_{2}$ concentration at the bottom of the combustor.

account the results of the experimental measurements, the average concentrations of $\mathrm{H}_{2}$ and $\mathrm{CO}$ with propane $\mathrm{C}_{3} \mathrm{H}_{8}$ were considered in a mathematical model with three types of exothermic chemical reactions to obtain the final products $\mathrm{H}_{2} \mathrm{O}, \mathrm{CO}_{2}$ :

1. $2 \mathrm{CO}+\mathrm{O}_{2} \rightarrow 2 \mathrm{CO}_{2}, 2 \mathrm{H}_{2}+\mathrm{O}_{2} \rightarrow 2 \mathrm{H}_{2} \mathrm{O}, 2 \mathrm{C}_{3} \mathrm{H}_{8}+3 \mathrm{O}_{2} \rightarrow 8 \mathrm{H}_{2}+6 \mathrm{CO}$ (three reactions with six species, $\mathrm{C}_{3} \mathrm{H}_{8}$ is the species of propane);

2. $\mathrm{C}_{3} \mathrm{H}_{8}+5 \mathrm{O}_{2} \rightarrow 3 \mathrm{CO}_{2}+4 \mathrm{H}_{2} \mathrm{O}$ (one reaction with four species);

3. $2 \mathrm{CO}+\mathrm{O}_{2} \rightarrow 2 \mathrm{CO}_{2}, 2 \mathrm{H}_{2}+\mathrm{O}_{2} \rightarrow 2 \mathrm{H}_{2} \mathrm{O}$ (two reactions with five species).

The following mass fractions for the species $C_{k}, k=\overline{1, K}$.

1. $K=6, C_{1}(C O), C_{2}\left(O_{2}\right), C_{3}\left(C_{2}\right), C_{4}\left(H_{2}\right), C_{5}\left(H_{2} O\right), C_{6}\left(C_{3} H_{8}\right.$ propane $)$,

2. $K=4, C_{1}\left(C_{3} H_{8}\right), C_{2}\left(O_{2}\right), C_{3}\left(C_{2}\right), C_{4}\left(H_{2} O\right)$,

3. $K=5, C_{1}(C O), C_{2}\left(O_{2}\right), C_{3}\left(C_{2}\right), C_{4}\left(H_{2}\right), C_{5}\left(H_{2} O\right)$,

were calculated for the nonlinear parabolic type PDEs. In the physical experiment, the obtained average values of the $\mathrm{CO}, \mathrm{H}_{2}\left[\mathrm{~mol} / \mathrm{m}^{3}\right]$ concentration, such as the mass fraction of concentration $C_{k}, \sum_{k=1}^{K} C_{k}=1$, were used in the mathematical model at the combustor inlet (the sum of reactants to equal unity, but that of the products was zero).

Assuming negligible thermal diffusion and equal constant multicomponent diffusion coefficients, the diffusive mass flux vector of the species is decreased to $-\rho D \nabla C_{k}$, and the species equation for the mass fraction $C_{k}$ reads as

$$
\rho \frac{D}{D t} C_{k}=\nabla \cdot\left(\rho D \nabla C_{k}\right)+m_{k} \Omega_{k},
$$


where $\frac{D}{D t}$ is a substantial derivative, $D=5 \cdot 10^{-5}\left[\mathrm{~m}^{2} / \mathrm{s}\right]$ is the constant molecular diffusivity of the species, $m_{k}[\mathrm{~g} / \mathrm{mol}]$ is the molecular weight of the $k$-th species, $\rho\left[\mathrm{kg} / \mathrm{m}^{3}\right]$ is the density of the mixture. The production rate for the $k$-th species can be written in the following form [29]:

$$
\Omega_{k}=\sum_{j=1}^{J}\left[\left(\nu_{j, k}^{\prime \prime}-\nu_{j, k}^{\prime}\right) R_{j}(T) \prod_{n=1}^{K}\left(\frac{\rho C_{n}}{m_{n}}\right)^{\nu_{j n}^{\prime}}\right], \quad k \in[1, K],
$$

where $J$ is the number of reactions, $R_{j}(T)$ is the rate constant modified by the Arrhenius temperature dependence for the forward path of the chemical reaction $R_{j}(T)=A_{j}^{\prime} T^{\beta_{j}} \exp \left(E_{j} / R T\right), A_{j}^{\prime}$ denotes the reaction-rate pre-exponential factors, $R=8.314\left[\mathrm{~J} /(\mathrm{mol} \mathrm{K}]\right.$ is the universal gas constant, $\nu_{j, k}^{\prime \prime}, \nu_{j, k}^{\prime}$ are the corresponding stoichiometric coefficients of the $k$-th species appearing as a product and reactant in the $j$-th reaction, $\beta_{j}$ is the order for the temperature. The molecular weight of the species is to be straightforwardly taken from the periodic table: $\mathrm{O}_{2}=32, \mathrm{CO}=28, \mathrm{CO}_{2}=44, \mathrm{H}_{2}=2, \mathrm{H}_{2} \mathrm{O}=18, \mathrm{C}_{3} \mathrm{H}_{8}=44$.

In the equation for the mass fractions of the concentration $C_{k}$ the source term is $m_{k} \Omega_{k} / \rho[1 / \mathrm{s}]$.

Under the assumption that the heat capacity does not depend on the temperature $T$, the specific heat at the constant pressure $c_{p}=1000[\mathrm{~J} /(\mathrm{kg} \mathrm{K})]$ and the thermal conductivity $\lambda=0.25[\mathrm{~J} /(\mathrm{smK})]$ are constant, and the only enthalpies needed are the enthalpies of the formation $h_{k}[\mathrm{~kJ} / \mathrm{mol}]$ to be determined from the tables [26] (for $H_{2}, c_{p}$ is approximely 14 [kJ/( $\left.\left.\mathrm{kg} \mathrm{K}\right)\right]$ (Cebeci [8]).

The temperature equation is

$$
\rho c_{p} \frac{D T}{D t}=\nabla \cdot(\lambda \nabla T)-\sum_{k=1}^{K} h_{k} \Omega_{k} m_{k} .
$$

In the equation for the temperature, the source term is $\frac{1}{m \rho c_{p}} \sum_{k=1}^{K} h_{k} m_{k} \Omega_{k}$ $[K / s]$, where $m=\frac{1}{K} \sum_{k=1}^{K} m_{k}$ is the mean molecular weight of the mixture.

The specific enthalpy of the $k$-th species $h_{k}$ is (Chemkin [27]):

$$
\mathrm{O}_{2}=0, C O=-111, \mathrm{CO}_{2}=-394, \mathrm{H}_{2}=0, \mathrm{H}_{2} \mathrm{O}=-242, \mathrm{C}_{3} H_{8}=-105 .
$$

\section{2D mathematical model}

For 2D modelling, an axially symmetric ideal, laminar, compressible swirling flow in a coaxial cylindrical pipe with the radius $r_{0}=0.05[\mathrm{~m}]$, length $z_{0}=0.1[\mathrm{~m}]$, radial and axial components of velocity $u_{r}, u_{z}$, circulation $v=r u_{\varphi}$ is considered using one reaction with propane and oxygen reactants for combustion. In the governing balance equations, some assumptions are made, i.e. constant physical properties, negligible soot and flame radiation, laminar flow, and validity of the ideal gas law. We focus on a configuration in which a steady low-velocity laminar flame exists in a straight pipe in the base state. The $2 \mathrm{D}$ mathematical model is described by the Navier-Stokes, temperature and four 
reaction-diffusion dimensionless equations in the cylindrical coordinates $(r, z)$ and at the time $t$ :

$$
\left\{\begin{array}{l}
\frac{\partial \rho}{\partial t}+M(\rho)+\rho\left(\frac{1}{r} \frac{\partial(r u)}{\partial r}+\frac{\partial w}{\partial x}\right)=0, \\
\frac{\partial u}{\partial t}+M(u)-S \frac{v^{2}}{r^{3}}=-\frac{1}{\rho} \frac{\partial p}{\partial r}+R e^{-1}\left(\Delta u-\frac{u}{r^{2}}\right), \\
\frac{\partial w}{\partial t}+M(w)=-\frac{1}{\rho} \frac{\partial p}{\partial x}+R e^{-1} \Delta w, \\
\frac{\partial v}{\partial t}+M(v)=R e^{-1} \Delta_{*} v, \\
\frac{\partial T}{\partial t}+M(T)=P_{0} \frac{1}{\rho} \Delta T+q_{1} \rho^{5} A_{1} C_{1} C_{2}^{5} \exp \left(-\frac{\delta_{1}}{T}\right), \\
\frac{\partial C_{1}}{\partial t}+M\left(C_{1}\right)=P_{1} \Delta C_{1}-\rho^{5} A_{1} C_{1} C_{2}^{5} \exp \left(-\frac{\delta_{1}}{T}\right), \\
\frac{\partial C_{2}}{\partial t}+M\left(C_{2}\right)=P_{2} \Delta C_{2}-5 \rho^{5} A_{1} C_{1} C_{2}^{5} \exp \left(-\frac{\delta_{1}}{T}\right) m_{2} / m_{1}, \\
\frac{\partial C_{3}}{\partial t}+M\left(C_{3}\right)=P_{3} \Delta C_{3}+3 \rho^{5} A_{1} C_{1} C_{2}^{5} \exp \left(-\frac{\delta_{1}}{T}\right) m_{3} / m_{1} \\
\frac{\partial C_{4}}{\partial t}+M\left(C_{4}\right)=P_{4} \Delta C_{4}+4 \rho^{5} A_{1} C_{1} C_{2}^{5} \exp \left(-\frac{\delta_{1}}{T}\right) m_{4} / m_{1},
\end{array}\right.
$$

where

$$
\Delta q=\frac{\partial^{2} q}{\partial x^{2}}+\frac{1}{r} \frac{\partial}{\partial r}\left(r \frac{\partial q}{\partial r}\right), \Delta_{*} q=\frac{\partial^{2} q}{\partial x^{2}}+r \frac{\partial}{\partial r}\left(\frac{1}{r} \frac{\partial q}{\partial r}\right), M(q)=w \frac{\partial q}{\partial x}+u \frac{\partial q}{\partial r} .
$$

Following Schlichting [28], in the Navier-Stokes equations in the cylindrical coordinates for the azimuthal component of velocity $u_{\varphi}=\frac{v}{r}$ the circulation $v$ is determined and this equation is multiplied by $r$.

With $C_{1}, C_{2}$ being the mass fractions of the reactants (propane $C_{3} H_{8}$ and oxygen $\left.\mathrm{O}_{2}\right), \mathrm{C}_{3}, \mathrm{C}_{4}$ the mass fractions of the products $\left(\mathrm{CO}_{2}, \mathrm{H}_{2} \mathrm{O}\right)$, in the exotermic reaction $\mathrm{C}_{3} \mathrm{H}_{8}+5 \mathrm{O}_{2} \rightarrow 3 \mathrm{CO}_{2}+4 \mathrm{H}_{2} \mathrm{O}, x=z / r_{0}, w=u_{z} / U_{0}, u=$ $u_{r} / U_{0}, v=r u_{\varphi}, q$ denotes any of the quantities $\rho, u, w, v, T, C_{k} ; P_{k}=D /\left(U_{0} r_{0}\right)$ $=0.01, k=1(1) 4, P_{0}=\lambda /\left(c_{p} \rho_{0} r_{0} U_{0}\right)=0.05, q_{1}=Q_{1} /\left(c_{p} T_{0}\right)=5, Q_{1}=\left(m_{1} h_{1}+\right.$ $\left.5 m_{2} h_{2}-3 m_{3} h_{3}-4 m_{4} h_{4}\right) /\left(m_{1} m\right),(\mathrm{J} / \mathrm{kg})$ is the heat loss in the reactions, $\delta_{1}=$ $E_{1} /\left(R T_{0}\right)=48.11$ is the scaled activation energy, $R=8.314(\mathrm{~J} /(\mathrm{mol} \mathrm{K})$ is the universal gas constant, $E_{1}=1.2 \cdot 10^{5}[\mathrm{~J} / \mathrm{mol}]$ (Martinez [24], Westley [33]) is the activation energy, $A_{1}=A_{1}^{\prime} \rho_{0}^{5} r_{0} /\left(U_{0} m_{2}^{5}\right)$ is the scaled pre-exponential factors, $A_{1}^{\prime}=14\left[m^{15} /\left(m o l^{5} s\right)\right], R e=U_{0} r_{0} \rho_{0} / \eta=10000$ is the Reynolds number, $\eta=$ $0.5 \cdot 10^{-6}(\mathrm{~kg} \mathrm{~s} / \mathrm{m})$ is the artificial viscosity. The value of the finite Reynolds number $R e$ is the stabilization factor to approximate the velocity equations.

The following parameters are also used: $P e=r_{0} U_{0} / D, L e=\lambda /\left(c_{p} D \rho_{0}\right)$ are the Peclet and Lewis numbers, $P_{0}=\frac{L e}{P e}, P_{k}=\frac{1}{P e}, k=1(1) 4, S=\frac{V_{0}}{U_{0}}$ is the swirl number. The equations were made dimensionless by scaling all the lengths to $r_{0}=0.05[\mathrm{~m}]$, the meridian velocity to $U_{0}=0.1[\mathrm{~m} / \mathrm{s}]$, the azimuthal velocity $u_{\varphi}$ to $V_{0}=0.3[\mathrm{~m} / \mathrm{s}]$, the temperature to $T_{0}=300[\mathrm{~K}]$, the density to $\rho_{0}=1\left[\frac{\mathrm{kg}}{\mathrm{m}^{3}}\right]$, the pressure to $\rho_{0} U_{0}^{2}$.

We introduced the stream function $\Psi$ and the vorticity $\zeta$ to the following 
expressions:

$$
r \rho w=\frac{\partial \Psi}{\partial r}, \quad r \rho u=-\frac{\partial \Psi}{\partial x}, \quad \zeta=\frac{\partial u}{\partial x}-\frac{\partial w}{\partial r} .
$$

Then the following equation for the stream function $\Psi$ is derived:

$$
\frac{\partial \Psi}{\partial t}=\frac{\partial}{\partial x}\left(\rho^{-1} \frac{\partial \Psi}{\partial x}\right)+r \frac{\partial}{\partial r}\left(\frac{1}{\rho r} \frac{\partial \Psi}{\partial r}\right)+r \zeta,
$$

where the equation for numerical simulation is transformed to a non-steady one. The approach seeks the steady solution as the limit of solutions of the unsteady equations.

The boundary of the pipe $\left(r=r_{0}\right)$ is subject to a heat loss modelled by the Newtonian cooling in ambient surroundings at a temperature $T_{0}$ and with the heat transfer coefficient $h=0.1\left[\frac{J}{s m^{2} K}\right]$.

The dimensionless boundary condition (BCs) are the following:

1) along the axis $r=0-u=v=0, \frac{\partial s}{\partial r}=0, s=T ; \rho ; w ; C_{k}, \Psi=0$,

2) at the wall $r=1-u=v=0, \frac{\partial T}{\partial r}+B i(T-1)=0, \frac{\partial s}{\partial r}=0, s=\rho$; $C_{k}, \Psi=q, \alpha \frac{\partial w}{\partial r}+(1-\alpha) w=0$,

$3)$ at the pipe outlet $x=x_{0}=\frac{z_{0}}{r_{0}}-u=0, \frac{\partial s}{\partial x}=0, s=\rho ; \Psi ; T ; C_{k} ; w ; v$,

4) at the pipe inlet $x=0-u=0, \rho=1$, and $w=1, T=1, C_{1}=C_{10}$, $C_{2}=C_{20}, C_{3}=C_{4}=v=0, \Psi=0.5 r^{2}$ for $r \in\left[0, r_{1}\right]$ and $w=0, T=1$, $C_{k}=0, \Psi=q, v=4\left(r-r_{1}\right)(1-r) /\left(1-r_{1}\right)^{2}$ for $r \in\left[r_{1}, 1\right]$ (we have a uniform jet flow at $r<r_{1}$ and the rotation at $r \geq r_{1}$ with the maximum azimuthal velocity when $\left.r=\left(1-r_{1}\right) / 2\right)$.

Here $q=\frac{r_{1}^{2}}{2}$ is the dimensionless fluid volume, $B i=\frac{h r_{0}}{\lambda}=0.1$ is the Biot number, $r_{1}=0.75, x_{0}=2, \alpha=\exp (-1000 / R e)$ is the characteristic parameter of no-slip conditions for the axial velocity $w$ depending on Re.

For the invisced laminar flow (large Re), we have the PDE of hyperbolic type. In this case, for the convective terms $M(q)$, we use the implicit FDS in time and the upwind diferences in space. The second-order derivatives are approximed with central differences.

For the stabilization of the calculations, in the first equation of Equations (4.1), the last terms with density (divergency) with the derivatives $\frac{\partial(r u)}{\partial r}$, $\frac{\partial w}{\partial x}$ are approximated by backward differences, but the terms with the pressure gradient $\frac{\partial p}{\partial r}, \frac{\partial p}{\partial z}(p=\rho T)$ are approximated by forward differences [20], [21]. In this case, we have a fast iteration process.

To solve the discrete problem, the ADI method of Duglas and Rachford [10] was used in the vector form of nine elements from unknown values in Equations (4.1). The discrete $2 \mathrm{D}$ problem with $40 \times 80$ uniform grid points and the time step $0.0008 \mathrm{~s}$ was solved. For the stationary solution with the maximum error $10^{-7}$, approximately 5000-7000 time steps were used (the final time $\left.t_{f}=5.1 \mathrm{~s}\right)$.

The boundary conditions for the species $C_{1}, C_{2}$ at the inlet $(x=0)$ are $C_{10}=$ $\overline{0.2,0.6}\left(C_{3} H_{8}\right), C_{20}=1-C_{10}\left(O_{2}\right)$ (see Table 1 for $t_{f}=10, M w=\max (w)$, 
$M T=\max (T), M u=\max (u), M C 3=\max \left(C_{3}\right), M C 4=\max \left(C_{4}\right), d p=$ $\max (p)-\min (p), m C 2=\min \left(C_{2}\right)$, Mro $=\max (\rho)$.

Finally, to prescribe the constant values on the Dirichlet portion of the boundary $x=0$, we used the stoichiometric ratio $s=\frac{0.044}{5 \cdot 0.032}=\frac{11}{40}$ and then solve the system for the mass fractions at stoichiometry:

$$
\left\{\begin{array}{l}
\frac{C_{1}}{C_{2}}=\frac{11}{40}, \\
C_{1}+C_{2}=1,
\end{array}\right.
$$

which yields $C_{10}=\frac{11}{51} \approx 0.22$ and $C_{20}=\frac{40}{51} \approx 0.78$. The values of products $C_{30}, C_{40}$ are set to zero at this segment of the boundary.

Table 1. Values of $M w, M u, M T, M C 3\left(\mathrm{H}_{2} \mathrm{O}\right), M C 4\left(\mathrm{CO}_{2}\right), m C 2\left(\mathrm{O}_{2}\right), d p$, Mro versus $C_{10}$

\begin{tabular}{ccccccccc}
\hline$C_{10}$ & $M w$ & $M u$ & $M T$ & $M C 3$ & $M C 4$ & $m C 2$ & $d p$ & $M r o$ \\
\hline 0.20 & $\mathbf{3 . 2 6}$ & 2.48 & $\mathbf{1 . 8 7}$ & $\mathbf{0 . 4 9}$ & $\mathbf{0 . 2 7}$ & 0.20 & $\mathbf{1 . 6 7}$ & 1.08 \\
0.22 & $\mathbf{3 . 2 6}$ & 2.48 & $\mathbf{1 . 8 7}$ & $\mathbf{0 . 4 9}$ & $\mathbf{0 . 2 7}$ & 0.19 & $\mathbf{1 . 6 7}$ & 1.08 \\
0.30 & 3.21 & 2.48 & 1.81 & 0.45 & 0.24 & 0.16 & 1.65 & 1.10 \\
0.40 & 3.10 & 2.49 & 1.69 & 0.37 & 0.20 & 0.16 & 1.59 & 1.15 \\
0.50 & 2.94 & 2.53 & 1.55 & 0.27 & 0.15 & 0.18 & 1.50 & 1.20 \\
0.60 & 2.42 & 2.59 & 1.06 & 0.03 & 0.01 & 0.35 & 0.90 & 1.00 \\
\hline
\end{tabular}

The results of the $2 \mathrm{D}$ modelling for the propane combustion at the small finite time $(t=5.1 \mathrm{~s})$ show that the maximum values of the products, temperature and axial velocity are obtained in the combustor with fixed (0.20-0.22) mass fractions of propane (see Table 1). In this case, the propane mass fraction at the outlet of the combustor was minimal. The calculation with $R e=10^{7}$ gave invariable results for these values. In the experimental studies, maxima of the temperature and of the $\mathrm{CO}_{2}$ at the bottom of the combustor at the $0.5 \mathrm{l} / \mathrm{min}$ propane flow at a large time (1000-2000 s) were obtained (see Figures 3-6).

Figures 7-16 illustrate the development of the temperature, axial velocity and concentrations in time $\left(t_{f}=0.4,5.1\right)$ and in space for $C_{1}=C_{10}=0.22$, $C_{2}=C_{20}=0.78$.

\section{$5 \quad 1 \mathrm{D}$ mathematical model}

For mathematical modelling, the 1D distribution of the axial component of velocity $u_{z}$, density $\rho$, mass fraction for different $K$ species and temperature $T$ has been calculated with the Matlab routine "pdepe" of the nonlinear parabolic type PDEs system, depending on the time $t$ and axial coordinate $z$ for six-nine unknown functions. The 1D distribution of the axial component of velocity $w=$ $u_{z} / U_{0},\left(U_{0}=0.1 \mathrm{~m} / \mathrm{s}\right)$, density $\rho / \rho_{0},\left(\rho_{0}=1 \mathrm{~kg} / \mathrm{m}^{3}\right)$, temperature $T / T_{0},\left(T_{0}=\right.$ $300 \mathrm{~K})$ and $K$ mass fractions $C_{k}$ at the time $t / t_{0},\left(t_{0}=1 \mathrm{~s}\right)$, using the axial coordinate $x=z / z_{0},\left(z_{0}=0.1 \mathrm{~m}\right)$ for $K+3$ unknown functions, was obtained.

For the mathematical modelling of the $1 \mathrm{D}$ compressible reacting swirling flow and density, we considered two parabolic type PDEs with $\rho, w(u=0)$ in 


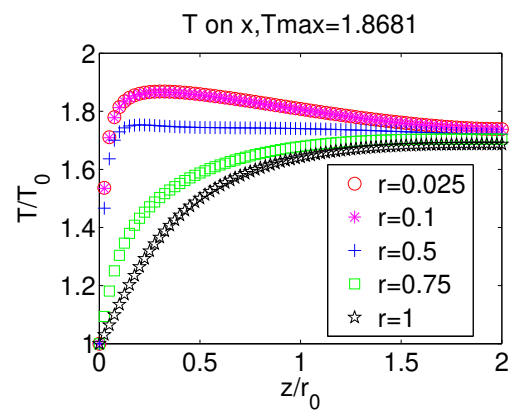

Figure 7. Temperature vs. $x$ with fixed $r$ and $t_{f}=5.1$.

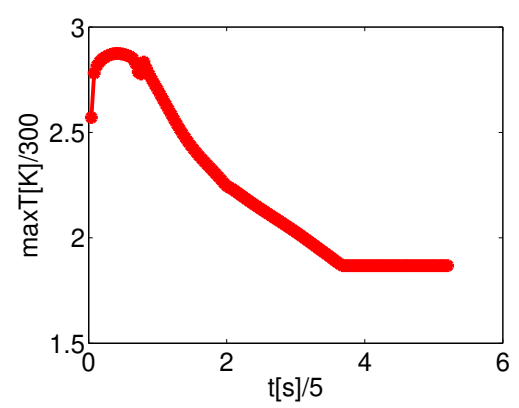

Figure 9. Maximum temperature vs. $t$ at $t_{f}=5.1$.

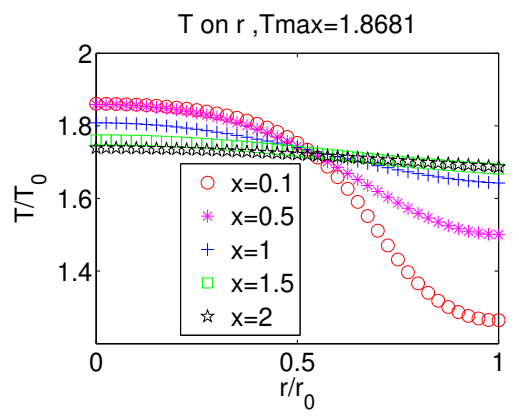

Figure 8. Temperature vs. $r$ with fixed $x$ and $t_{f}=5.1$.

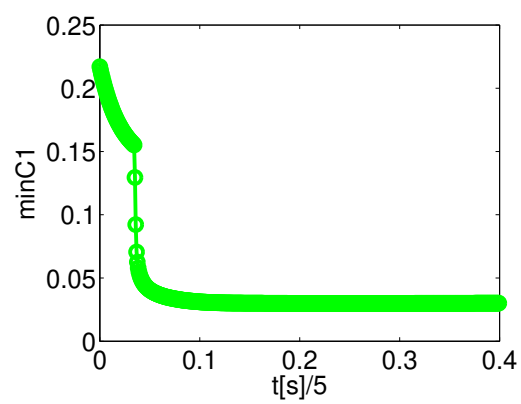

Figure 10. Minimum concentration of propane vs. $t$ at $t_{f}=0.4$.

the following dimensionless form:

$$
\left\{\begin{array}{l}
\frac{\partial \rho}{\partial t}+M(\rho)+\rho \frac{\partial w}{\partial x}=e \frac{\partial^{2} \rho}{\partial x^{2}} \\
\frac{\partial w}{\partial t}+M(w)=-\frac{\partial p}{\rho \partial x}+R e^{-1} \frac{\partial^{2} w}{\partial x^{2}}
\end{array}\right.
$$

where $M(s)=w \frac{\partial s}{\partial x}, s=\rho, w, C_{k}, R e=10000$ and $e=10^{-5}$ are the factors of the artificial viscosity to approximate the velocity and density with upwind differences in discrete equations.

The BCs at the inlet $(x=0)$ are $\rho=w=T=1$. These values are used as initial conditions at $t=0$. At the outlet, zero derivatives conditions are applied. Numerical results depending on $(x, t)$ are obtained for $x \in[0,2], t \in$ $\left[0, t_{f}\right], t_{f}=1 ; 10$. At the thermo-chemical conversion of biomass pellets and their mixtures, maximum values of the temperature max $T$, axial flow velocity $\max w$ and of the mass fractions of species were obtained. 


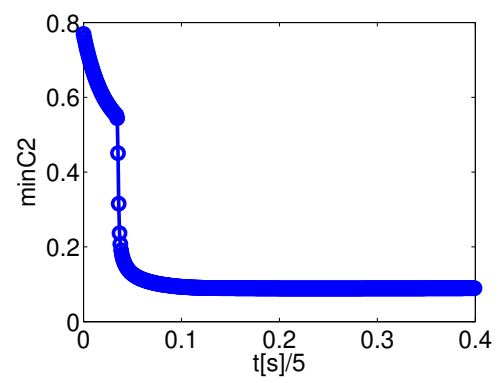

Figure 11. Minimum concentration of $\mathrm{O}_{2}$ vs. $t$ at $t_{f}=0.4$.

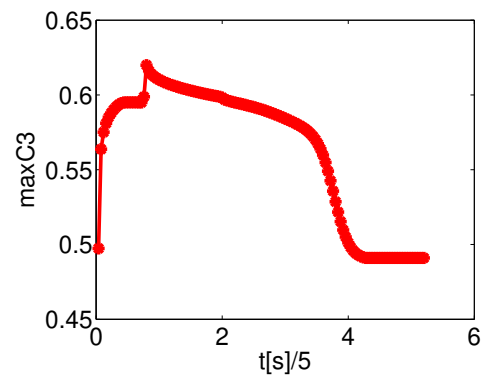

Figure 13. Maximum concentration of $\mathrm{H}_{2} \mathrm{O}$ vs. $t$ at $t_{f}=5.1$.

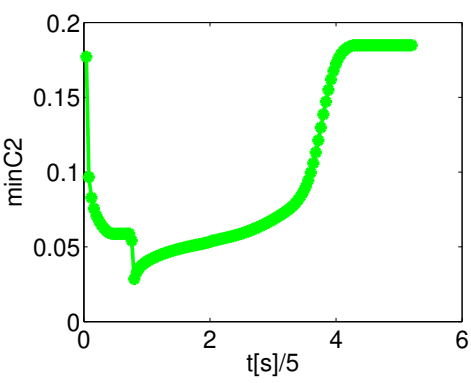

Figure 12. Minimum concentration of $O_{2}$ vs. $t$ at $t_{f}=5.1$.

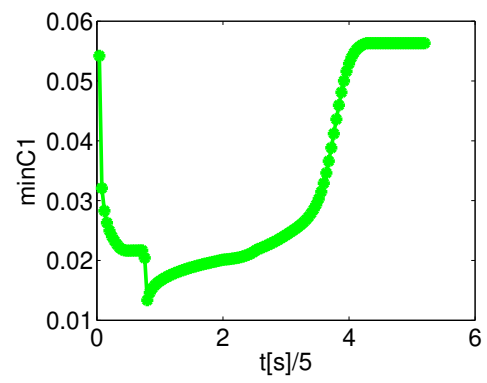

Figure 14. Minimum concentration of propane vs. $t$ at $t_{f}=5.1$.

\subsection{First type reaction: $2 \mathrm{CO}+\mathrm{O}_{2} \rightarrow 2 \mathrm{CO}_{2}, 2 \mathrm{H}_{2}+\mathrm{O}_{2} \rightarrow 2 \mathrm{H}_{2} \mathrm{O}$, $2 \mathrm{C}_{3} \mathrm{H}_{8}+3 \mathrm{O}_{2} \rightarrow 8 \mathrm{H}_{2}+6 \mathrm{CO}$}

For the mathematical modelling of the first type reactions, we consider the following dimensionless equations for six chemical species and for the temperature:

$$
\left\{\begin{array}{l}
\frac{\partial T}{\partial t}+M(T)=\frac{P_{0}}{\rho} \frac{\partial^{2} T}{\partial x^{2}}+q_{1} \rho^{2} A_{1} T^{\beta_{1}} C_{1}^{2} C_{2} \exp \left(-\frac{\delta_{1}}{T}\right) \\
+q_{2} \rho^{2} A_{2} T^{\beta_{2}} C_{2} C_{4}^{2} \exp \left(-\frac{\delta_{2}}{T}\right)+q_{3} \rho^{4} A_{3} T^{\beta_{3}} C_{2}^{3} C_{6}^{2} \exp \left(-\frac{\delta_{3}}{T}\right) \\
\frac{\partial C_{1}}{\partial t}+M\left(C_{1}\right)=P_{1} \frac{\partial^{2} C_{1}}{\partial x^{2}}-2 \rho^{2} A_{1} T^{\beta_{1}} m_{1} / m_{2} C_{1}^{2} C_{2} \exp \left(-\frac{\delta_{1}}{T}\right) \\
\quad+6 \rho^{4} A_{3} T^{\beta_{3}} m_{1} / m_{2} C_{2}^{3} C_{6}^{2} \exp \left(-\frac{\delta_{3}}{T}\right), \\
\frac{\partial C_{2}}{\partial t}+M\left(C_{2}\right)=P_{2} \frac{\partial^{2} C_{2}}{\partial x^{2}}-\rho^{2} A_{1} T^{\beta_{1}} C_{1}^{2} C_{2} \exp \left(-\frac{\delta_{1}}{T}\right) \\
\quad-\rho^{2} A_{2} T^{\beta_{2}} C_{2} C_{4}^{2} \exp \left(-\frac{\delta_{2}}{T}\right)-3 \rho^{4} A_{3} T^{\beta_{3}} C_{2}^{3} C_{6}^{2} \exp \left(-\frac{\delta_{3}}{T}\right) \\
\frac{\partial C_{3}}{\partial t}+M\left(C_{3}\right)=P_{3} \frac{\partial^{2} C_{3}}{\partial x^{2}}+2 \rho^{2} A_{1} T^{\beta_{1}} m_{3} / m_{2} C_{1}^{2} C_{2} \exp \left(-\frac{\delta_{1}}{T}\right) \\
\frac{\partial C_{4}}{\partial t}+M\left(C_{4}\right)=P_{4} \frac{\partial^{2} C_{4}}{\partial x^{2}}-2 \rho^{2} A_{2} T^{\beta_{2}} m_{4} / m_{2} C_{4}^{2} C_{2} \exp \left(-\frac{\delta_{2}}{T}\right)
\end{array}\right.
$$




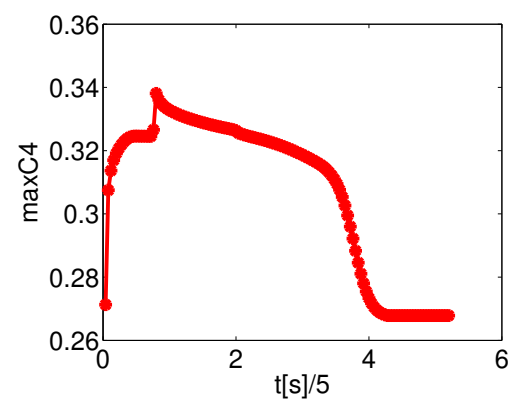

Figure 15. Maximum concentration of $\mathrm{CO}_{2}$ vs. $t$ at $t_{f}=5.1$.

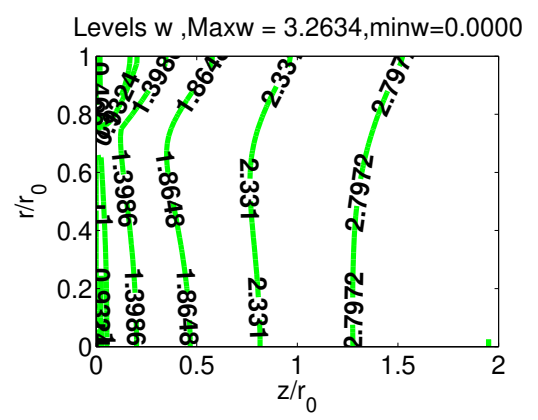

Figure 16. Levels of the axial velocity at $t_{f}=5.1$.

$$
\left\{\begin{array}{l}
+8 \rho^{4} A_{3} T^{\beta_{3}} m_{4} / m_{2} C_{2}^{3} C_{6}^{2} \exp \left(-\delta_{3} / T\right), \\
\frac{\partial C_{5}}{\partial t}+M\left(C_{5}\right)=P_{5} \frac{\partial^{2} C_{5}}{\partial x^{2}}+2 \rho^{2} A_{2} T^{\beta_{2}} m_{5} / m_{2} C_{2} C_{4}^{2} \exp \left(-\frac{\delta_{2}}{T}\right), \\
\frac{\partial C_{6}}{\partial t}+M\left(C_{6}\right)=P_{6} \frac{\partial^{2} C_{6}}{\partial x^{2}}-2 \rho^{4} A_{3} T^{\beta_{3}} m_{6} / m_{2} C_{2}^{3} C_{6}^{2} \exp \left(-\frac{\delta_{3}}{T}\right),
\end{array}\right.
$$

where $\left.q_{k}=Q_{k} / c_{p} T_{0}\right), k=1,2,3 ; ' Q_{1}=\left(2 m_{1} h_{1}+m_{2} h_{2}-2 m_{3} h_{3}\right) /\left(m_{2} m\right)$, $Q_{2}=\left(m_{2} h_{2}+2 m_{4} h_{4}-2 m_{5} h_{5}\right) /\left(m_{2} m\right), Q_{3}=\left(-6 m_{1} h_{1}+3 m_{2} h_{2}-8 m_{4} h_{4}+\right.$ $\left.2 m_{6} h_{6}\right) /\left(m_{2} m\right)$ are the heat losses for each reaction $[\mathrm{J} / \mathrm{kg}], P_{k}=D_{k} /\left(U_{0} z_{0}\right)=$ $0.01, P_{0}=\lambda /\left(c_{p} \rho_{0} U_{0} z_{0}\right)=0.05, \lambda=0.25[\mathrm{~W} /(\mathrm{m} . \mathrm{K})]$ is the thermal conductivity, $D_{k}=5 \cdot 10^{-5}\left[\mathrm{~m}^{2} / \mathrm{s}\right]$ is the molecular diffusivity of species, $\delta_{j}=E_{j} /\left(R T_{0}\right)$ stands for the scaled activation energies, $R=8.314[\mathrm{~J} / \mathrm{mol} \mathrm{K}]$ is the universal gas constant, $A_{1}=A_{1}^{\prime} \rho_{0}^{2} z_{0} /\left(U_{0} m_{1}^{2}\right), \beta_{1}=\beta_{2}=\beta_{3}=0, A_{2}=A_{2}^{\prime} \rho_{0}^{2} z_{0} /\left(U_{0} m_{4}^{2}\right)$, $A_{3}=A_{3}^{\prime} \rho_{0}^{4} z_{0} /\left(U_{0} m_{2}^{2} m_{6}^{2}\right)$ are the scaled reaction-rate pre-exponential factors, $A_{1}^{\prime}=1500\left[\mathrm{~m}^{6} / \mathrm{mol}^{2} \mathrm{~s}\right], A_{2}^{\prime}=190\left[\mathrm{~m}^{6} / \mathrm{mol}^{2} \mathrm{~s}\right], A_{3}^{\prime}=140\left[\mathrm{~m}^{12} / \mathrm{mol}^{4} \mathrm{~s}\right], E_{1}=$ $E_{2}=E_{3}=120000[\mathrm{~J} / \mathrm{mol}][24]$.

The BCs for $C_{6}, C_{2}$ at the inlet $(x=0)$ are $C_{60}=\{0.25,0.8\}\left(C_{3} H_{8}\right)$, $C_{20}=1-C_{60}\left(O_{2}\right)$ (see Table 2 for $t_{f}=10$, Ckend $=C_{k}\left(2, t_{f}\right), k=1,3,4,5,6$; $C 2$ end $=0\left(\mathrm{O}_{2}\right)$. We can also obtain the BCs from the stoichiometric ratio $s=$ $\frac{2 \cdot 0.044}{3 \cdot 0.032}=\frac{11}{12}$ and then solve the system for the mass fractions at stoichiometry:

$$
\left\{\begin{array}{l}
\frac{C_{6}}{C_{2}}=\frac{11}{12}, \\
C_{6}+C_{2}=1,
\end{array}\right.
$$

which gives $C_{20}=\frac{12}{23} \approx 0.52$ and $C_{60}=\frac{11}{23} \approx 0.48$.

The products $C_{10}, C_{30}, C_{40}, C_{50}$ are set to zero on this segment of the boundary. These boundary conditions at the inlet were used as initial conditions at $t=0$. At the outlet, the zero derivatives conditions were used. The mass fraction of the reactant $\mathrm{O}_{2}$ decreased to zero at $t=t_{f}$.

The results of $1 \mathrm{D}$ modelling for the propane combustion (similar to $2 \mathrm{D}$ modelling) at the finite time $\left(t_{f}=10 \mathrm{~s}\right)$ demonstrate that maximum values of the products, temperature, axial velocity are obtained with the 0.25 mass fractions of propane. The numerical results depending on $(x, t)$ are listed in 
Table 2: $M w=\max (w), M T=\max (T)$, Tend $=T\left(2, t_{f}\right)$, wend $=w\left(2, t_{f}\right)$, Ckend $=C_{k}\left(2, t_{f}\right)$. For the mass fractions of the combustible volatiles $C O, H_{2}$, maximum are obtained at $C_{60} \geq 0.7$. This is in accord with the results of the experimental measurements at the outlet of the gasifier (Figure 2) when the maximum of the concentration $\mathrm{CO}, \mathrm{H}_{2}$ is obtained at the propane injection $0.5 \mathrm{l} / \mathrm{min}$.

Table 2. Values of $M w$, wend, $M T$, Tend, $\mathrm{Clend}(\mathrm{CO}), \mathrm{C} 3 \operatorname{end}\left(\mathrm{CO}_{2}\right), \mathrm{C} 4 \mathrm{end}\left(\mathrm{H}_{2}\right)$, $\mathrm{C} 5$ end $\left(\mathrm{H}_{2} \mathrm{O}\right), \mathrm{C} 6$ end $\left(\mathrm{C}_{3} \mathrm{H}_{8}\right)$ versus $\mathrm{C}_{60}$.

\begin{tabular}{cccccccccc}
\hline$C_{60}$ & $M w$ & wend & $M T$ & Tend & C1end & C3end & C4end & C5end & C6end \\
\hline 0.25 & 3.57 & $\mathbf{2 . 2 2}$ & $\mathbf{1 0 . 9}$ & $\mathbf{5 . 1 0}$ & 0.0 & 0.74 & 0.0 & $\mathbf{0 . 4 0}$ & 0.0 \\
0.28 & 3.38 & 2.20 & 10.6 & 4.90 & 0.01 & 0.79 & 0.01 & 0.38 & 0.01 \\
0.3 & 3.69 & 2.14 & 10.3 & 4.59 & 0.02 & $\mathbf{0 . 8 1}$ & 0.01 & $\mathbf{0 . 2 4}$ & 0.02 \\
0.35 & 4.09 & 2.05 & 10.1 & 4.08 & 0.07 & 0.79 & 0.02 & 0.27 & 0.04 \\
0.4 & $\mathbf{4 . 1 4}$ & 1.98 & 9.55 & 3.76 & 0.12 & 0.78 & 0.03 & 0.22 & 0.07 \\
0.5 & 3.56 & 1.87 & 8.11 & 3.34 & 0.20 & 0.68 & 0.04 & 0.15 & 0.17 \\
0.6 & 3.03 & 1.76 & 7.01 & 3.03 & 0.28 & 0.54 & 0.05 & 0.09 & 0.27 \\
0.7 & 2.83 & 1.61 & 5.73 & 2.76 & 0.31 & 0.39 & 0.05 & 0.06 & 0.40 \\
0.8 & 2.82 & 1.34 & 4.56 & 2.45 & $\mathbf{0 . 3 2}$ & 0.24 & $\mathbf{0 . 0 5}$ & 0.03 & 0.55 \\
\hline
\end{tabular}

The time (final time $t_{f}=10$ ) and space variations of the temperature and concentrations at $C_{60}=0.4$ are displayed in Figures 17-22.

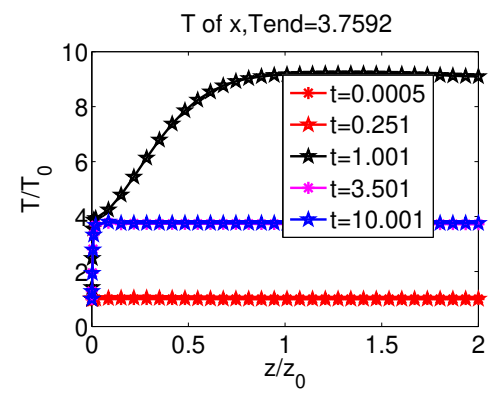

Figure 17. Temperature vs. $x$ with fixed $t$.

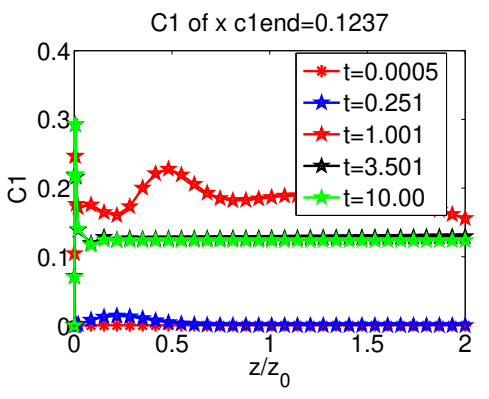

Figure 18. $C O$ concentration vs. $x$ with fixed $t$.

\subsection{Second type reactions: $\mathrm{C}_{3} \mathrm{H}_{8}+5 \mathrm{O}_{2} \rightarrow 3 \mathrm{CO}_{2}+4 \mathrm{H}_{2} \mathrm{O}$}

For the mathematical modelling of this reaction (similar to $2 \mathrm{D}$ modelling) for four chemical species and for the temperature, we use Eqs. (4.1). The BCs for $C_{1}, C_{2}$ at the inlet $(x=0)$ are $C_{10}=\overline{0.1,0.7}\left(C_{3} H_{8}\right), C_{20}=1-C_{10}\left(O_{2}\right)$ (see Table 3 with $t_{f}=10$ ). From the other algorithm it follows that $\frac{C_{1}}{C_{2}}=$ $\frac{11}{40}, C_{1}+C_{2}=1$ or $C_{10}=0.22, C_{20}=0.78$.

The maximum values of $\mathrm{MT}, \mathrm{Mw}$, wend, Tend, $\mathrm{CO}_{2}, \mathrm{H}_{2} \mathrm{O}$ were obtained (similar to $2 \mathrm{D}$ modelling) for $C_{10}=0.2$ when the propane mass fraction at the 


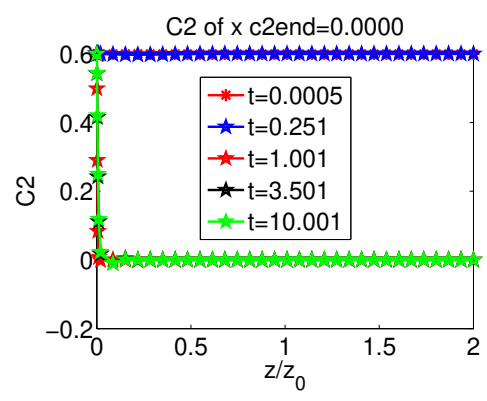

Figure 19. $\mathrm{O}_{2}$ concentration vs. $x$ with fixed $t$.

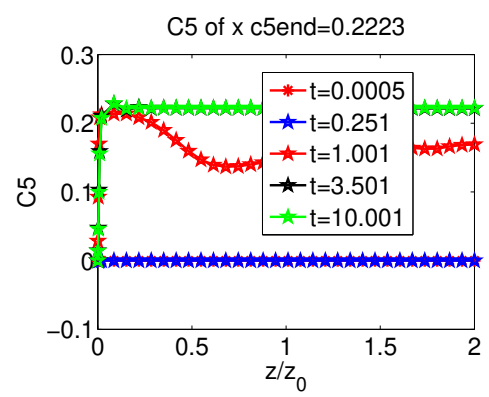

Figure 21. $\mathrm{H}_{2} \mathrm{O}$ concentration vs. $x$ with fixed $t$.

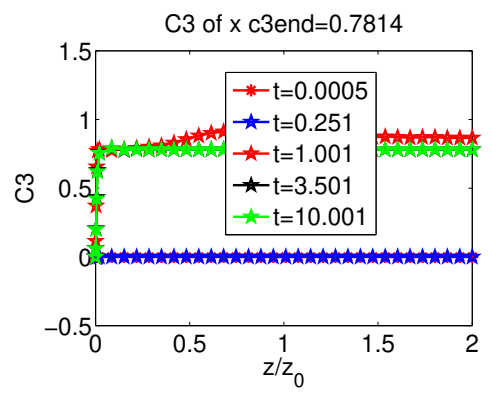

Figure 20. $\mathrm{CO}_{2}$ concentration vs. $x$ with fixed $t$.

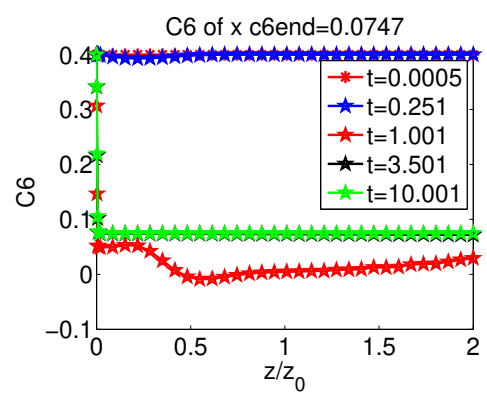

Figure 22. Propane $\mathrm{C}_{3} \mathrm{H}_{8}$ concentration vs. $x$ with fixed $t$.

outlet $x=2, C 1$ end $=0.004$. For $C_{10}=0.1, C 1 e n d=0$, but the mass fractions of $\mathrm{O}_{2} \mathrm{C} 2 \mathrm{end}=0.54$ (the mass fraction for propane at the inlet was too small).

Figures 23-28 illustrate the development of the temperature, axial velocity and concentration in time $\left(t_{f}=10\right)$ and in space for $C_{1}=C_{10}=0.4, C_{2}=$ $C_{20}=0.6$.

\subsection{Third type reactions: $2 \mathrm{CO}+\mathrm{O}_{2} \rightarrow 2 \mathrm{CO}_{2}, 2 \mathrm{H}_{2}+\mathrm{O}_{2} \rightarrow 2 \mathrm{H}_{2} \mathrm{O}$}

According to the results of the experimental measurements at the outlet of the gasifier (Figures 1-2), the average concentrations of $\mathrm{H}_{2}$ and $\mathrm{CO}$ were used in the chemical reactions of the mathematical model to obtain the final products $\mathrm{H}_{2} \mathrm{O}, \mathrm{CO}_{2}$, where $\mathrm{O}_{2}$ is the third reactant in the reactions. Referring to the experimental data, the average values of $C_{1}(C O)$ and $C_{4}\left(H_{2}\right)$ at the inlet of the combustor depending on the propane injection qprop are the following $\left(\frac{m o l}{m^{3}}=\frac{g / m^{3}}{g / m o l}, m\left(H_{2}\right)=2 \frac{g}{m o l}, m(C O)=28 \frac{g}{m o l}\right):$

1*) $0.16[\mathrm{l} / \mathrm{min}]-H_{2}=1.65\left[\mathrm{~mol} / \mathrm{m}^{3}\right], C O=1.82\left[\mathrm{~mol} / \mathrm{m}^{3}\right]$;

$\left.2^{*}\right) 0.33[\mathrm{l} / \mathrm{min}]-H_{2}=1.35\left[\mathrm{~mol} / \mathrm{m}^{3}\right], C O=1.71\left[\mathrm{~mol} / \mathrm{m}^{3}\right]$;

$\left.3^{*}\right) 0.44[\mathrm{l} / \mathrm{min}]-H_{2}=2.00\left[\mathrm{~mol} / \mathrm{m}^{3}\right], C O=2.39\left[\mathrm{~mol} / \mathrm{m}^{3}\right]$;

$\left.4^{*}\right) 0.56[\mathrm{l} / \mathrm{min}]-H_{2}=1.50\left[\mathrm{~mol} / \mathrm{m}^{3}\right], C O=2.11\left[\mathrm{~mol} / \mathrm{m}^{3}\right]$;

$\left.5^{*}\right) 0.62[\mathrm{l} / \mathrm{min}]-H_{2}=1.30\left[\mathrm{~mol} / \mathrm{m}^{3}\right], C O=1.82\left[\mathrm{~mol} / \mathrm{m}^{3}\right]$. 
Table 3. Values of $M w$, wend, $M T$, Tend, $C 1 e n d\left(\mathrm{C}_{3} \mathrm{H}_{8}\right), C 2 e n d\left(\mathrm{O}_{2}\right), C 3 e n d\left(\mathrm{CO}_{2}\right)$, $\mathrm{C} 4$ end $\left(\mathrm{H}_{2} \mathrm{O}\right)$ versus $\mathrm{C}_{10}$.

\begin{tabular}{ccccccccc}
\hline$C_{10}$ & $M w$ & wend & $M T$ & Tend & C1end & C2end & C3end & C4end \\
\hline 0.1 & 4.48 & 1.61 & 4.78 & 2.11 & 0.00 & 0.54 & 0.30 & 0.16 \\
0.2 & $\mathbf{6 . 6 4}$ & $\mathbf{1 . 9 7}$ & $\mathbf{8 . 4 8}$ & $\mathbf{3 . 6 7}$ & 0.01 & 0.09 & $\mathbf{0 . 5 9}$ & $\mathbf{0 . 3 2}$ \\
0.3 & 6.41 & 1.93 & 7.91 & 3.52 & 0.12 & 0.04 & 0.54 & 0.30 \\
0.4 & 5.64 & 1.87 & 7.02 & 3.27 & 0.25 & 0.04 & 0.46 & 0.25 \\
0.5 & 4.71 & 1.81 & 6.23 & 3.04 & 0.37 & 0.04 & 0.38 & 0.21 \\
0.6 & 4.50 & 1.73 & 5.21 & 2.82 & 0.50 & 0.04 & 0.30 & 0.16 \\
0.7 & 2.83 & 1.61 & 4.17 & 2.59 & 0.63 & 0.04 & 0.22 & 0.12 \\
\hline
\end{tabular}

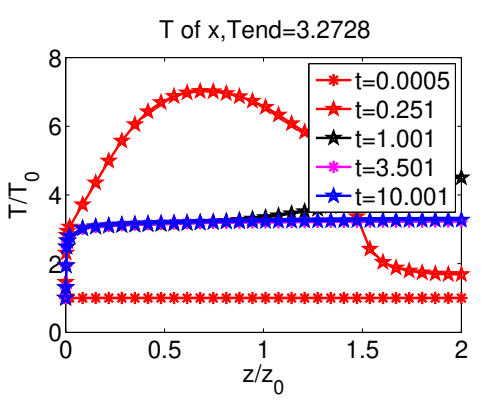

Figure 23. Temperature vs. $x$ with fixed $t$.

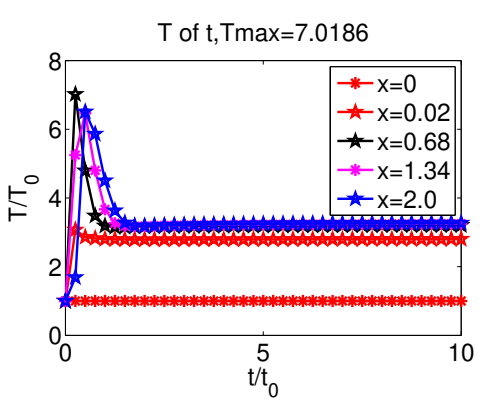

Figure 24. Temperature vs. time $t$ with fixed $x$.

These values were used in the mathematical model as the concentration mass fraction $C_{k}, k=1(1) 5$ for the initial conditions, decreasing thus these values by about five times. Here $C_{1}+C_{2}+C_{4}=1$ (the mass factions of the reactants) and $C_{3}=C_{5}=0$ (the mass factions of the products). To obtain the temperature and mass fractions of the species, we used the first type reactions without the propane reaction (with Eqs. 5.1) with $A_{3}=0$.)

The BCs at the inlet $x=0-C_{1}=C_{10}(C O), C_{2}=C_{20}\left(O_{2}\right), C_{4}=C_{40}\left(H_{2}\right)-$ depend on five different injections of propane.

The numerical results determined by $(x, t)$ are summarized in Table 4 at $t_{f}=1, C 2 e n d=0\left(O_{2}\right)$.

In Table 4 , it is seen that for propane injections qprop $2^{*}$ and $5^{*}$, maximum values of the temperature, axial velocity and mass fractions of the products $\mathrm{CO}_{2}, \mathrm{H}_{2} \mathrm{O}$ are obtained when the mass fraction of $\mathrm{O}_{2}$ is maximum at the inlet. The concentration of the products increases in time. The mass fraction of the reactants $\mathrm{CO}, \mathrm{H}_{2}$ in the reactions at a small time moment $(\mathrm{t}=0.5[s])$ decreases, and for $\mathrm{O}_{2}$ decreases to zero for all propane injections.

For injection $5^{*}$, Figures 29-32 show the variation of the temperature and concentrations of $H_{2}, C O$ in space $x \in[0,2]$ at $t_{f}=10$. The results of the mathematical modelling show that, in accordance with the data of the experimental study, the maximum values of the flame temperature, axial flow velocity and mass fractions of the main products $\left(\mathrm{CO}_{2}, \mathrm{H}_{2} \mathrm{O}\right)$ at the thermo-chemical con- 


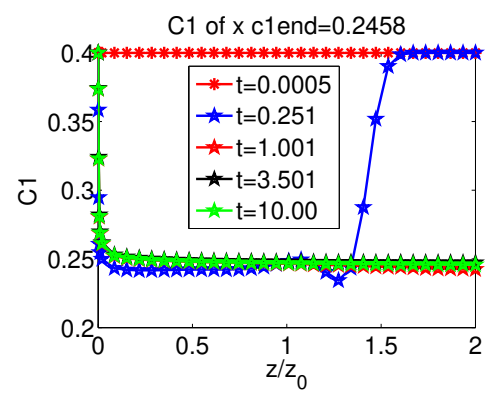

Figure 25. Propane $\mathrm{C}_{3} \mathrm{H}_{8}$ concentration vs. $x$ with fixed $t$.

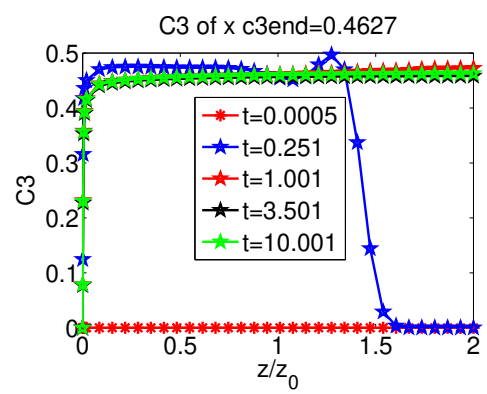

Figure 27. $\mathrm{CO}_{2}$ concentration vs. $x$ with fixed $t$.

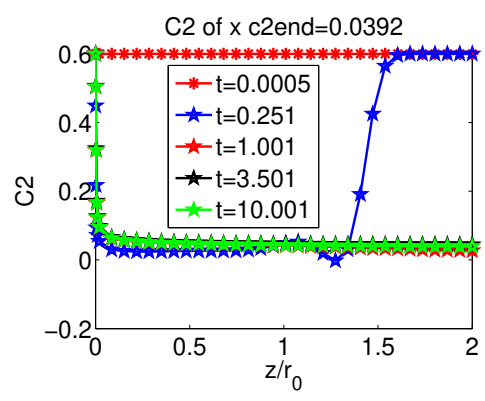

Figure 26. $\mathrm{O}_{2}$ concentration vs. $x$ with fixed $t$.

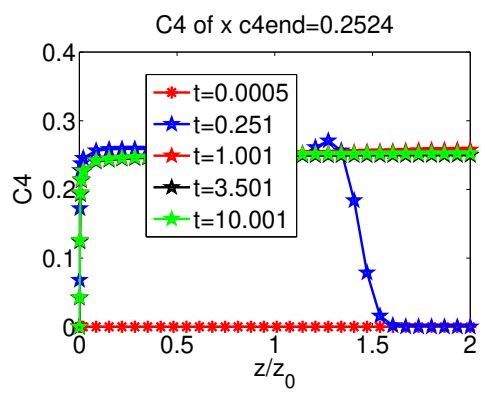

Figure 28. $\mathrm{H}_{2} \mathrm{O}$ concentration vs. $x$ with fixed $t$.

version of the biomass pellets and their mixtures were obtained for the fixed magnitude of the propane flow when co-firing straw with a gas. The results of the mathematical modelling for the propane combustion give evidence that the maximum values of the products are obtained for 0.33 and $0.62 \mathrm{l} / \mathrm{min}$ of the propane supply (see Table 4). In the experiments, the maximum of the temperature and $\mathrm{CO}_{2}$ was obtained at $0.5 \mathrm{l} / \mathrm{min}$ (Figures $3-4$ ).

In following Table 5 it is seen the comparison values of Tend, obtained in experiment $_{\text {Tend }} d_{\text {exp }}$ and in modelling Tend ${ }_{\text {mod }}$ for 4 series of propane injections qprop $\left(1^{*}, 2^{*}, 4^{*}, 5^{*}\right)$ (see Figure 34 ), the errors $\Delta T_{i}=\operatorname{Tend}_{\text {exp } i}-$ Tend $_{\text {modi }}, \delta T_{i}=$ $\frac{\sum_{i=1}^{n} \Delta T_{i}}{n}-\Delta T_{i}$, for calculation the error $V_{k}=\sqrt{\sum_{i=1}^{n}\left(\delta T_{i}\right)^{2} /(n(n-1))}=$ $27.16[K]$ or $20.3 \%$ corresponding to errors $\Delta T_{i}$ averaging value $133.5[\mathrm{~K}](\mathrm{n}=4)$. Similarly results are obtained for maximum values of temperature TM: $V_{k}=$ $53.58[K]$ or $22.1 \%$ corresponding to averaging error $242.5[\mathrm{~K}]$.

We can see that $T M_{\text {mod }}>T M_{\exp }$. Using the chemical reaction the flame temperature by $t=0.2 s, x=0.68(z=0.068 \mathrm{~m})$ rapidly increases to its maximum value $1149 \mathrm{~K}$ and then decreases in the time and space $(t=10 \mathrm{~s}, x=2.0)$ to $T$ end $=570 K$ (see Figure 32 for propane injection $5^{*}$ ).

In following Figures 33-34 we represent the concentration of species CO in experiment $\left[\mathrm{g} / \mathrm{m}^{3}\right]$ at the inlet and calculated mass fraction at the outlet and temperature at the outlet Tend in experiment and modelling depends on propane injection qprop $[\mathrm{l} / \mathrm{min}]$. 
Table 4. Values of $M w$, wend, $M T$, Tend, Ckend, $k=1,3,4,5, t_{f}=10$.

\begin{tabular}{lccccc}
\hline$C_{k}$ & $1 *$ & $2 *$ & $3 *$ & $4 *$ & $5 *$ \\
\hline$C_{10}(\mathrm{CO})$ & 0.36 & 0.34 & 0.44 & 0.42 & 0.36 \\
$C_{40}\left(\mathrm{H}_{2}\right)$ & 0.33 & 0.27 & 0.32 & 0.30 & 0.26 \\
$C_{20}\left(\mathrm{O}_{2}\right)$ & 0.31 & 0.39 & 0.24 & 0.28 & 0.38 \\
$\mathrm{C}_{\operatorname{end}}\left(\mathrm{H}_{2} \mathrm{O}\right)$ & 0.26 & $\mathbf{0 . 3 3}$ & 0.18 & 0.21 & $\mathbf{0 . 3 0}$ \\
$\mathrm{C} 4 \operatorname{end}\left(\mathrm{H}_{2}\right)$ & 0.30 & 0.23 & 0.29 & 0.28 & 0.23 \\
$\mathrm{C} 3 \operatorname{end}(\mathrm{CO})$ & 0.22 & 0.28 & 0.26 & 0.27 & $\mathbf{0 . 3 0}$ \\
$\mathrm{C} 1 \mathrm{end}(\mathrm{CO})$ & 0.22 & 0.16 & 0.28 & 0.25 & 0.17 \\
$\operatorname{Mw}[\mathrm{m} / \mathrm{s}]$ & 0.44 & $\mathbf{0 . 4 7}$ & 0.41 & 0.44 & $\mathbf{0 . 4 7}$ \\
wend $[\mathrm{m} / \mathrm{s}]$ & 0.15 & $\mathbf{0 . 1 6}$ & 0.15 & 0.15 & $\mathbf{0 . 1 6}$ \\
$\operatorname{Tend}[\mathrm{K}]$ & 525 & $\mathbf{5 7 0}$ & 510 & 522 & $\mathbf{5 7 0}$ \\
$M T[\mathrm{~K}]$ & 954 & $\mathbf{1 1 4 6}$ & 970 & 939 & $\mathbf{1 1 4 9}$ \\
\hline
\end{tabular}

Table 5. Values of qprop $[1 / \mathrm{min}], \operatorname{Tend}_{\exp }[K], T e n d_{m o d}[K], \Delta T, \delta T, T M_{\text {exp }}, T M_{\text {mod }}$

\begin{tabular}{ccccccc}
\hline qprop & Tend $_{\text {exp }}$ & Tend $_{\text {mod }}$ & $\Delta T$ & $\delta T$ & $T M_{\text {exp }}$ & $T M_{\text {mod }}$ \\
\hline 0.16 & 583 & 525 & 58 & 75.5 & 783 & 954 \\
0.33 & 700 & 570 & 130 & 3.5 & 797 & 1140 \\
0.56 & 698 & 522 & 176 & -42.5 & 808 & 939 \\
0.62 & 740 & 570 & 170 & -36.5 & 824 & 1149 \\
\hline
\end{tabular}

Differences in curve trends are mainly determined by (in our opinion) the two main factors - first of all that the difference is in experiment for air predominance. So the $\mathrm{CO}_{2}$ concentration in the channel outlet is lower, and the $\mathrm{CO}$ is higher than the stoichiometric combustion process calculations. Secondly, it is possible that the burning process is not over until the channel exit. This is essentially confirmed by measurements of the efficiency of the combustion process, which is relatively low at the channel outlet and does not exceed $80 \%$. The results of experimental study and mathematical modelling have shown that the composition and temperature of the products at co-firing straw with propane is strongly influenced by the propane supply into the device (Figures $33,34)$. The enhanced development of the endothermic processes at the thermal decomposition of straw promotes a correlating increase of the molar fraction of $\mathrm{CO}$ at the outlet of the gasifier (Figure 2) determining a decrease of the temperature at the outlet of the device (Figure 34). Difference between the results of the experimental study and mathematical modelling is predominately determined by the difference in length of the experimental device $\left(\mathrm{L}=z_{0}=0.4 \mathrm{~m}\right)$ and cylindric pipe $\left(z_{0}=0.1 \mathrm{~m}\right)$, which is used for the mathematical modelling of the processes developing at straw co-firing with propane. The local increase of the molar fraction of $\mathrm{CO}$ with correlating decrease of the flow temperature at this distance $\left(z_{0}=0.1\right)$ suggest incomplete combustion of volatiles on the development of the thermochemical conversion of straw and the flame temperature, as it follows from the results of mathematical modelling (Table 4 and 


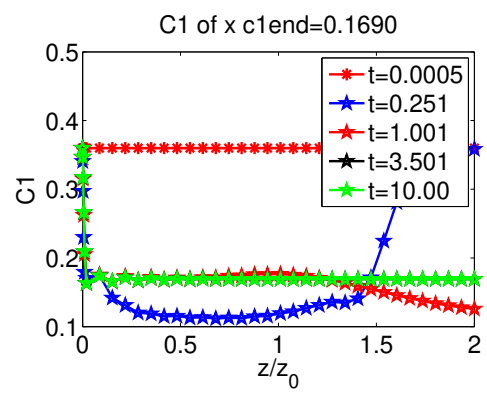

Figure 29. Concentration of $C O$ vs. $x$ with fixed $t$.

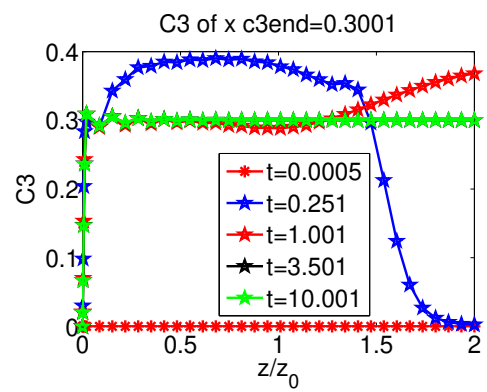

Figure 31. Concentration of $\mathrm{CO}_{2}$ vs. $x$ with fixed $t$.

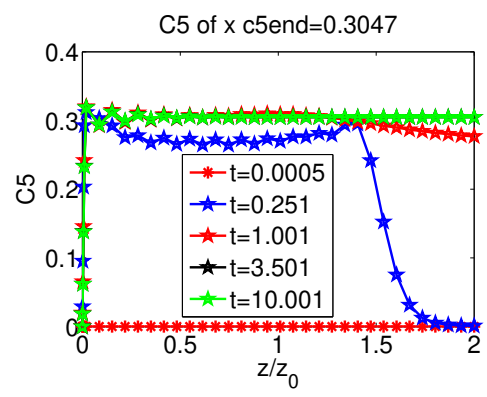

Figure 30. Concentration of $\mathrm{H}_{2} \mathrm{O}$ vs. $x$ with fixed $t$.

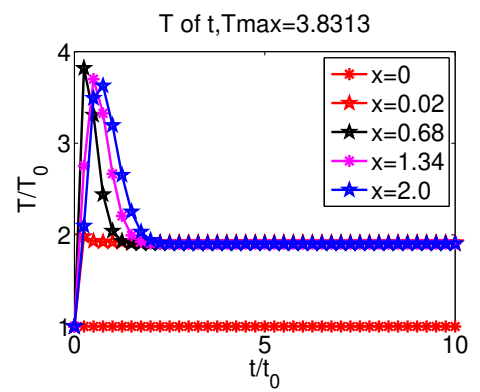

Figure 32. Temperature $T$ vs. $t$ with fixed $x$.

Figure 34). Complete combustion of volatiles is observed further downstream $\left(z_{0}=0.4\right)$, when a decrease of the molar fraction of volatiles in the products correlates with an increase of the flame temperature (Figure 3 ) and temperature at the outlet of the device (Figure 34).

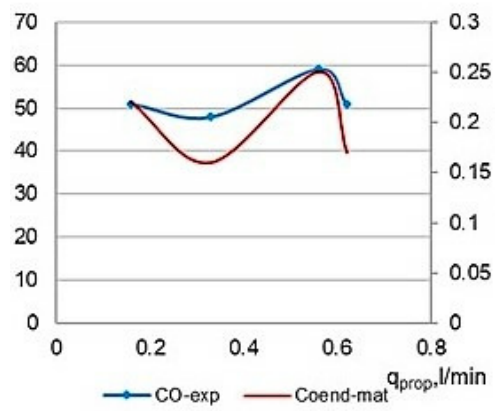

Figure 33. Concentration of species $\mathrm{CO}$ in experiment $\left[\mathrm{g} / \mathrm{m}^{3}\right]$ at the inlet and calculated mass fraction $\mathrm{C} 1 \mathrm{end}$ at the outlet depends on propane injection qprop $[1 / \mathrm{min}]$.

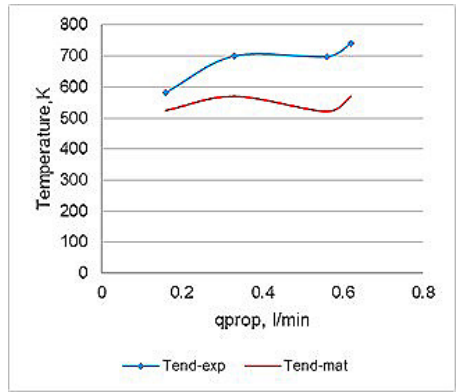

Figure 34. Comparision Tend in experiment and modelling at the outlet depends on propane injection qprop $[1 / \mathrm{min}]$. 


\section{Conclusions}

Because of complexity the processes developing during straw co-firing with propane the comparison of the results of experimental study and mathematical modelling is rather qualitative, but still to be considered as a productive collaboration between the partners. The results of the performed mathematical modelling have shown that, in accordance with the data of the experimental study the main flame characteristics (flow velocity, flame temperature and composition of the products) are influenced by the variations of the propane supply into the device responsible for the enhanced thermal decomposition of straw, the formation, ignition and burnout of combustible volatiles $\left(\mathrm{CO}, \mathrm{H}_{2}\right)$.

The results of $1 \mathrm{D}$ and $2 \mathrm{D}$ modelling of the processes developing at co-firing of straw with propane demonstrate that the maximum value of the molar fraction of the products and flame temperature for the stoichiometric combustion conditions can be achieved during the relatively small time period $(t<10 \mathrm{~s})$ and refer to the mass fraction of propane $0.2-0.25$ at the inlet of the combustor. In the experiments of straw co-firing with propane, which were developing at the air excess ratio in the flame reaction zone and were lasting up to $2400 \mathrm{~s}$, the propane supply into the device causes a decrease of the molar fraction of combustible volatiles in the products to the minimum value with correlating increase of the flame temperature and the $\mathrm{CO}_{2}$ volume fraction in the products up to the peak values, which for the conditions of the air excess supply were observed at the higher propane supply into the device $-0.5 \mathrm{l} / \mathrm{min}$.

Differences in curve run are mainly determined, in our opinion, by the difference in length of the reaction zone downstream the experimental device and by the reduced length of the reaction zone, which is used at mathematical modelling of straw co-firing.

The results presented above prove that the additional heat supply during co-firing of straw with propane flame flow makes it possible to control the thermal decomposition of straw pellets, the formation, ignition and the combustion of volatiles and the development of combustion dynamics, completing the combustion of biomass and leading to cleaner heat energy production.

\section{Acknowledgements}

The authors would like to express their gratitude for the financial support from the European Regional Funding for a project SAM 1.1.1.1/16/A/004.

\section{References}

[1] M. Abricka, I. Barmina, R. Valdmanis, M. Zake and H. Kalis. Experimental and numerical studies on integrated gasification and combustion of biomass. Chemical Engineering Transactions, 50:127-132, 2016.

[2] I. Barmina, A. Kolmickovs, R. Valdmanis, M. Zake, H. Kalis and U. Strautins. Electric field effect on the thermal decomposition and co-combustion of straw pellets with peat. Chemical Engineering Transactions, 70:1267-1272, 2018.

[3] I. Barmina, A. Lickrastina, M. Zake, A. Arshanitsa, A. Solodovnik and G. Telysheva. Experimental study of thermal decomposition and combustion of ligno- 
cellulosic biomass pellets. Latvian Journal of Physics and Technical Sciences, 50(3):35-48, 2013. https://doi.org/10.2478/lpts-2013-0018.

[4] I. Barmina, R. Valdmanis and M. Zake. Control of the development of the swirling airflow dynamics and its impact on the biomass combustion characteristics. Latvian Journal of Physics and Technical Sciences, 54(3):30-39, 2017. https://doi.org//10.1515/lpts-2017-0018.

[5] I. Barmina, R. Valdmanis, M. Zake, H. Kalis, M. Marinaki and U. Strautins. Magnetic field control of combustion dynamics. Latvian Journal of Physics and Technical Sciences, 53(4):36-47, 2016. https://doi.org/10.1515/lpts-2016-0027.

[6] I. Barmina, R. Valdmanis, M. Zake, L. Ozola and U. Strautins. Development of gasification/combustion characteristics at thermochemical conversion of biomass mixtures. In J. Palabinskis Latvia University of Agriculture(Ed.), Proc. of the 16th Int. Conf. on Engineering for Rural Development(ERDev17), Jelgava, Latvia, May 24-26, 2017, Engineering for Rural Development, pp. 54-59, 2017.

[7] M. Brown and R.W. Judd. Emission reduction through biomass and gas co-firing the bagit project. 23th World Gas Conference, Amsterdam, p. 13, 2006.

[8] T. Cebeci and P. Gradshaw. Physical and computational aspects of convective heat transfer. Spriger-Verlag, 1984.

[9] J.J. Choi, Z. Rusak and A.K. Kapila. Numerical simulation of promixed chemical reactions with swirl. Combustion Theory and Modelling, 6(11):863-887, 2007. https://doi.org/10.1080/13647830701256085.

[10] J. Douglas and R. Rachford. On the numerical solution of heat conduction problems in two and three space variables. Trans. Amer. Math. Soc., 82(2):421439, 1956. https://doi.org/10.2307/1993056.

[11] EU. 2020 climate and energy package. Climate strategies and targets, 2012.

[12] N.J. Glithero, P. Wilson and S. Ramsden. Straw use and availability for second generation biofuels in england. Biomass and Bioenergy, 55:311-321, 2013. https://doi.org/10.1016/j.biombioe.2013.02.033.

[13] A.K. Gupta, D.G. Lilley and N. Syred. Swirl Flows. Abacus Press, 1984.

[14] H. Kalis, I. Barmina, M. Zake and A. Koliskins. Mathematical modelling and experimental study of electrodynamic control of swirling flame flows. In J. Palabinskis Latvia University of Agriculture(Ed.), Proc. of the 15-th Int. Conf. on Engineering for Rural Development(ERDev16), Jelgava, Latvia, May 25-27, 2016, Engineering for Rural Development, pp. 134-141, 2016.

[15] H. Kalis, A. Kolmickovs, M. Marinaki and L. Ozola. Development of combustion dynamics at co-combustion of straw with wood. In J. Palabinskis Latvia University of Agriculture(Ed.), Proc. of the 17-th Int. Conf. on Engineering for Rural Development(ERDev18), Jelgava, Latvia, May 23-25, 2018, Engineering for Rural Development, pp. 1322-1328, 2018.

[16] H. Kalis, M. Marinaki, L. Ozola, U. Strautins, I. Barmina and M. Zake. Mathematical modelling on electromagnetic field control of the combustion process. Magnetohydrodynamics, 53(4):687-698, 2017. https://doi.org/10.22364/mmp2017.36.

[17] H. Kalis, M. Marinaki, U. Strautins and I. Barmina. Influence of electric field on thermo-chemical conversion of mixtures of straw pellets with coal. In J. Palabinskis Latvia University of Agriculture(Ed.), Proc. of the 17-th Int. Conf. on Engineering for Rural Development(ERDev18), Jelgava, Latvia, May 23-25, 2018, Engineering for Rural Development, pp. 1746-1753, 2018. 
[18] H. Kalis, M. Marinaki, U. Strautins and O. Lietuvietis. On the numerical simulation of the combustion process with simple chemical reaction. In Dmitri Meshumayev and Bength Sunden(Eds.), Proc. of the 7-th Baltic Heat Transfer Conference, Tallinn, Estonia, Aug. 24-26, 2015, Baltic Heat Transfer Conference BHTC, pp. 175-180, 2015.

[19] H. Kalis, M. Marinaki, U. Strautins and O. Lietuvietis. On the numerical simulation of the vortex breakdown in the combustion process with simple chemical reaction and axial magnetic field. Int. Jour. of Differential Equations and Applications, 14(3):235-250, 2015.

[20] H. Kalis, M. Marinaki, U. Strautins and M. Zake. On numerical simulation of electromagnetic field effects in the combustion process. Mathematical Modelling and Analysis, 23(2):324-343, 2018. https://doi.org/10.3846/mma.2018.020.

[21] V.M. Kovenya and N.N. Yanenko. The method of decomposition in gas dynamical problems. Nauka Press Novosibirtsk in Russian, 1981.

[22] C.K. Law. Combustion Physics. Cambridge, 2006.

[23] D.G. Lilley. Swirl flows in combustion, a review. AIAA Journal, 15(8):17631778, 1977.

[24] I. Martinez. Combustion kinetics, set of lectures. http://webserver.dmt.upm.es/isidoro/bk3/c15/Combustion.pdf, p. 47, 2014.

[25] D. Nordgren, H. Hedman, N. Padban, D. Bostromm and M. Ohman. Ash transformation in pulverised fuel co-combustion of straw and woody biomass. Fuel Processing Technology, 105:52-58, 2013. https://doi.org/10.1016/j.fuproc.2011.05.027.

[26] J.M. Powers. Lectures notes of Fundamentals of Combustion. Notre Dame, Indiana, USA, 2012.

[27] Sandia National Laboratories Report SAND87-8215B. Chemkin Collection release 3.6, The Chemkin Thermodynamic Database. Reaction Design, Inc., San Diego, CA, 2000.

[28] H. Schlichting. Grenzschicht Theorie, 5-te Auflage. Verlag G. Braun, Karlsruhe; Nauka,Moscow 1969 - in Russian, 1965.

[29] M.D. Smooke, A.A. Turnbull, R.E. Mitchella and D.E. Keyes. Solution of twodomensional axysymmetric laminar diffusion flames by adaptive boundary value methods. NATO ASI Series E: Applied Sciences, 140:261-300, 1987.

[30] N. Syred and J.M. Beer. Combustion on swirling flows, a review. Combustion and Flame, 23:143-201, 1974. https://doi.org/10.1016/0010-2180(74)90057-1.

[31] National Energy Technology Laboratory (NETL) U.S. Department of Energy. Biomass cofiring program. Program Facts, 2000.

[32] S.V. Vassilev, D. Baxter, L.K. Andersen and Ch.G. Vassileva. An overview of the chemical composition of biomass. Fuel, 89:913-933, 2010. https://doi.org/10.1016/j.fuel.2009.10.022.

[33] F. Westley. Table of Recommended Rate Constants for Chemical Reactions Occurring in Combustion. National Bureau of Standards, Washington, 1980.

[34] M. Zake, I. Barmina and M. Lubane. Swirling flame. Part 1. Experimental study of the effect of stage combustion on soot formation and carbon sequestration from the nonpremixed swirling flame. Magnetohydrodynamics, 40(2):161-181, 2004. 